\title{
ALGORITHMS IN MATLAB TO COMPUTE A LOCAL GEOID MODEL FOR GEOMATICS PURPOSES
}

\author{
Massimiliano PEPE${ }^{1}$ (1)
}

DOI: 10.21163/GT_2022.171.06

\begin{abstract}
:
The aim of the paper is to show a methodology in order to build a local geoid model using the ComputeRemove-Restore technique; to achieve this aim, suitable algorithms in Matlab ${ }^{\circledR}$ environment were developed. The knowledge of a geoid model assumes an important role in the field of engineering, geosciences and geomatics since that it allows the definition of physical heights or the components of the deflection of the vertical on a specific area. The area taken into consideration for the research is the Campania region (Italy). By comparing the geoid undulation values of the model developed in this paper with those extracted from the benchmarks over this area derived from the national levelling network, it is possible to obtain centimetre accuracy.
\end{abstract}

Key-words: Geoid, Compute-Remove-Restore, EGM, Physical geodesy.

\section{INTRODUCTION}

Physical geodesy is the science of the figure of the Earth and its gravity field (HofmannWellenhof \& Moritz, 2006). A surface of particular interest for geomatics purposes is the geoid, i.e. an equipotential surface of the Earth gravity field (Sansò \& Sideris, 2013). The geoid can be computed from knowledge of the gravitational field. The most commonly used technique for determining the regional geoid model is the "Remove-Compute-Restore" (RCR) technique which it is based on theory of the first-order approximation of either Molodensky's method for quasi-geoid determination or the classical geoid modelling by Helmert's second method of condensing the topography onto the geoid (Sjöberg, 2005). The RCR technique is the only practical geoid gravimetric modelling technique for combining terrestrial gravimetric data with an Earth Gravity Mode - EGM (Torge, 2001). Indeed, the recent global geopotential models, based on the CHAMP (Challenging Minisatellite Payload, a German BMBF-funded geophysical mini-satellite mission of GFZ-GeoForschungsZentrum) and GRACE (Gravity Recovery and Climate Experiment, a joint mission of National Aeronautics and Space Administration - NASA and the German Aerospace Center - DLR) space missions, have allowed to obtain high-performance local geoid models, as shown in Barzaghi et al., 2007 for the estimation of the gravimetric quasi-geoid named ITALGEO05.

RCR technique was applied with success in several country over the time. For example, Blázquez et al., 2003 show the good results of the regional model called ANDALUSGeoid2002 obtained using fast collocation method and the RCR Procedure. Lysaker et al., 2007 dicussed of the quasi-geoid evaluation with improved levelled height data for Norway region. El-Ashquer et al, 2017 have developed an hybrid gravimetric geoid model HGM2016 by means of least-squares collocation method and remove-compute-restore process over Egypt. Kalu et al., 2021 wrote about the RCR technique in modelling a gravimetric geoid model for a large data deficient region in West Africa (Nigeria) using two sets of long and short wavelength data (a) EGM2008 (long) + Airborne

${ }^{1}$ Polytechnic of Bari, via E. Orabona 4, 70125 Bari, Italy, massimiliano.pepe@poliba.it 
gravimetric observation (AGO) dataset (short) (b) EGM2008 (long) + Terrestrial gravimetric undulation (TGU) dataset (short).

The realization of a regional geoid model and, consequently, the knowledge of geoid undulation and vertical deviation components contributes positively in considerable geomatics applications. For example, Barzaghi et al., 2016 used the deflection of the vertical components obtained from a local model for the correction of External Orientation (EO) parameters (attitude angles) in Direct Georeferencing (DG) photogrammetry approach. In addition, the usefulness of the regional model in order to transform the ellipsoid height in orthometric in Global Navigation Satellite Systems (GNSS) measurements was applied in serval geomatics works present in literature (Baiocchi et al., 2017: Parente \& Pepe, 2018; Oluyori et al., 2019; Erol et al., 2020; Pepe et al., 2020; Costantino et al., 2021).

In this paper, a study for the computation of a local geoid model at a spatial resolution $\left(2.5^{\prime}\right)$ is addressed, using the following methods: $i)$ Remove-Compute-Restore technique; ii) constant and vertical shift of the EGM2008 geoid undulation model.

\section{STUDY AREA}

The study area taken into consideration concerns the Campania region, an administrative region of south Italy; most of it is in the south-western portion of the Italian peninsula (with the Tyrrhenian Sea to its west), but it also includes the small Phlegraean Islands and the island of Capri. The morphology of this territory is mainly hilly $(51 \%)$; the remaining part of the territory is mountainous $(34 \%)$ and flat $(15 \%)$. It covers an area of $13670.95 \mathrm{~km}^{2}$. The area taken into consideration, reported in Fig. 1, is contained within the geographical coordinates: $39^{\circ} \mathrm{N} \leq \varphi \leq 42^{\circ} \mathrm{N}$ and $13^{\circ} \mathrm{E} \leq \lambda \leq 16^{\circ} \mathrm{E}$.

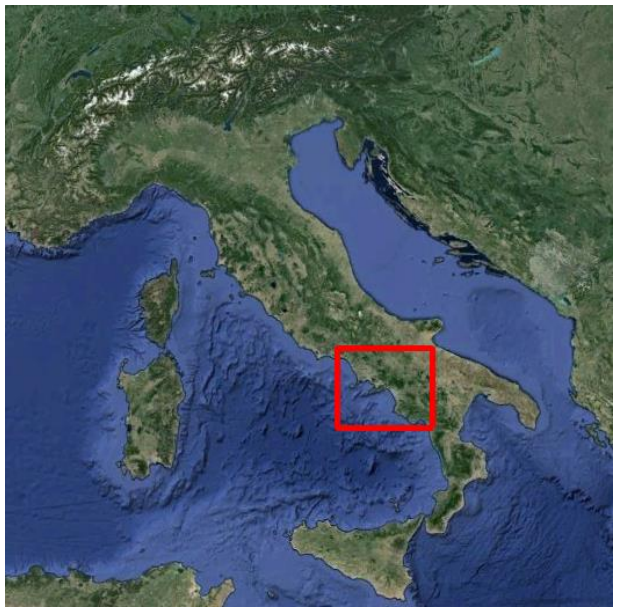

(a)

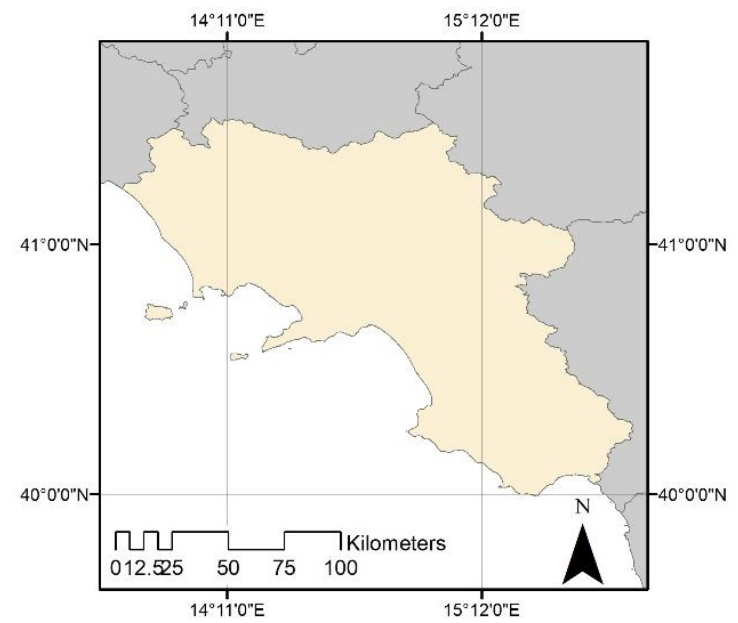

(b)

Fig. 1. Area of interest (AOI) to compute local geoid model; view on Google earth (a) and geographic framework (b).

\section{DATA AND METHODS}

\subsection{Remove-Compute-Restore technique}

The compute of any quantity of the gravity field is carried out by means of a frequency analysis of the quantity itself, i.e. the following three components are identified: i) low-frequency component, represented by global geopotential models (e.g. Earth Gravity Model - EGM2008); ii) mediumfrequency component, which it can be calculated on the basis of local data and; iii) high-frequency 
component, which can be linked to the topographic effect and is calculated on the basis of a digital terrain model (Corchete et al., 2005).

The "Remove-Compute-Restore" technique can be schematised into the following points:

- Remove: removal of the contribution of the global model (determined by a spherical harmonic model) and of an additional contribution called "Residual Terrain Correction" (RTC) representing the effect of the masses between the topography and a reference surface;

- Compute: calculation of co-geoid undulation residuals;

- Restore: addition, in terms of geoid undulation, of both that of the global model and that of the RTC effect, also called "indirect topographic effect".

These steps can be summarised as reported below (Srinivas et al., 2012):

$$
N=N_{G M}+N_{\text {ind }}+N_{\Delta g}
$$

where the geoid undulation values are derived from:

$$
\begin{array}{ll}
N_{G M} & \text { global geoid model; } \\
N_{\text {ind }} & \text { the indirect effect; } \\
N_{\Delta g} & \text { from the residues of gravity anomalies. }
\end{array}
$$

\subsubsection{Contribution of global geoid model}

The long-wavelength geoid component $N_{G M}$ is obtained by the use of a global geopotential model; currently, the most widely used model is the EGM2008 (Pavlis et al., 2007; Pavlis et al. 2008; Pavlis et al., 2021) publicly released by the U.S. National Geospatial-Intelligence Agency (NGA) EGM Development Team which is derived from data from the GRACE satellite (Mayer-Gürr et al., 2016), topographic data (Saleh et al., 2002) and ground-based gravimetric observations.

The EGM2008 model was developed up to degree and order 2159 , which results in a spatial resolution of the model of about 2.5' where the values of the vertical deviation and gravimetric anomalies are freely available at the NGA address.

Computationally, the current $W$ potential expressed in terms of spherical polar coordinates, radius, longitude, latitude $(r, \lambda, \psi)$, is described by the coefficients $C_{n m}$ and $S_{n m}$ of degree $\mathrm{n}$ and order $\mathrm{m}$, which are empirically determined and associated with the Legendre polynomial $P_{n m}$ (Borre, 2008):

$$
W(r, \lambda, \psi)=\frac{\mathrm{GM}}{\mathrm{r}}\left[1+\sum_{\mathrm{n}=2}^{\mathrm{n}_{\max }}\left(\frac{\mathrm{a}}{\mathrm{r}}\right)^{\mathrm{n}} \sum_{m=0}^{n}\left(\bar{C}_{n m} \cos \mathrm{m} \lambda+\bar{S}_{n m} \sin \mathrm{m} \lambda\right) \bar{P}_{n m}(\sin \psi)\right]
$$

where GM is the product of Newton's gravitational constant and Earth's total mass (including the atmosphere), $a$ is the radius of the bounding sphere and $r$ is the geocentric radius.

Recalling that the anomalous potential $T$ is the difference between the one of the gravitational field $W$ and the gravitational normal one $U$, it follows that in the hypothesis to know the anomalous potential $T$, it is possible to write with the formula of Bruns, the anomalous height $\zeta$ :

$$
\zeta=\frac{T}{\gamma}
$$

Therefore, the previous equation becomes:

$$
\zeta(r, \lambda, \psi)=\frac{\mathrm{GM}}{\gamma(\varphi) r}\left[\sum_{\mathrm{n}=2}^{\mathrm{n}_{\max }}\left(\frac{\mathrm{a}}{\mathrm{r}}\right)^{\mathrm{n}} \sum_{m=0}^{n}\left(\bar{C}_{n m} \cos \mathrm{m} \lambda+\bar{S}_{n m} \sin \mathrm{m} \lambda\right) \bar{P}_{n m}(\sin \psi)\right]
$$

where the value of normal gravity $\gamma(\varphi)$ is equal to:

$$
\gamma(\varphi)=\frac{\gamma_{e} \cos ^{2} \varphi+(1-f) \gamma_{p} \sin ^{2} \varphi}{\sqrt{\cos ^{2} \varphi+(1-f)^{2} \sin ^{2} \varphi}}
$$

while at height $h$, the value of normal gravity $\gamma(\mathrm{h})$ takes on the following expression: 


$$
\gamma(\mathrm{h})=\gamma(\varphi)\left[1-2\left(1+f+m-2 f \sin ^{2} \varphi\right) \frac{h}{a}+3\left(\frac{h}{a}\right)^{2}\right]
$$

In addition, the geoid undulation $N$ is related to the ellipsoid height $h$ measured along the normal to the ellipsoid, the orthometric height $H$, the normal height $H^{*}$ and the anomalous height $\zeta$, by equation (Heiskanen and Moritz, 1967):

$$
N=H^{*}-H+\zeta
$$

Furthermore, orthometric height is related to normal height through the relationship:

$$
H=H^{*}-\frac{\Delta g_{B}}{\gamma(\mathrm{h})} H
$$

where $\Delta g_{B}$ represents the Bouguer anomaly.

Finally, it is possible to calculate the value of the gravity anomaly of the global geopotential model with the following relation (Heiskanen and Moritz, 1967; Kuroishi,1993):

$$
\Delta g_{G M}=\frac{G M}{r^{2}} \sum_{n=2}^{n_{\max }}(n-1)\left(\frac{a}{r}\right)^{n} \sum_{m=0}^{n} \bar{P}_{n m}(\sin \varphi)\left(\bar{C}_{n m} \cos \mathrm{m} \lambda+\bar{S}_{n m} \sin m \lambda\right)+\Delta g_{0}
$$

where $\Delta g_{0}$ is the term of degree 0 .

\subsubsection{Contribution of the indirect effect}

The removing or moving of masses changes the potential gravity and, consequently, the geoid; this change of the geoid is called indirect effect of gravity reduction. Therefore, the surface calculated with Stokes' formula does not refer to the geoid but to a slightly different surface, the co-geoid (Fig. 2), from which it is possible to extrapolate, using Bruns' theorem, the following formula:

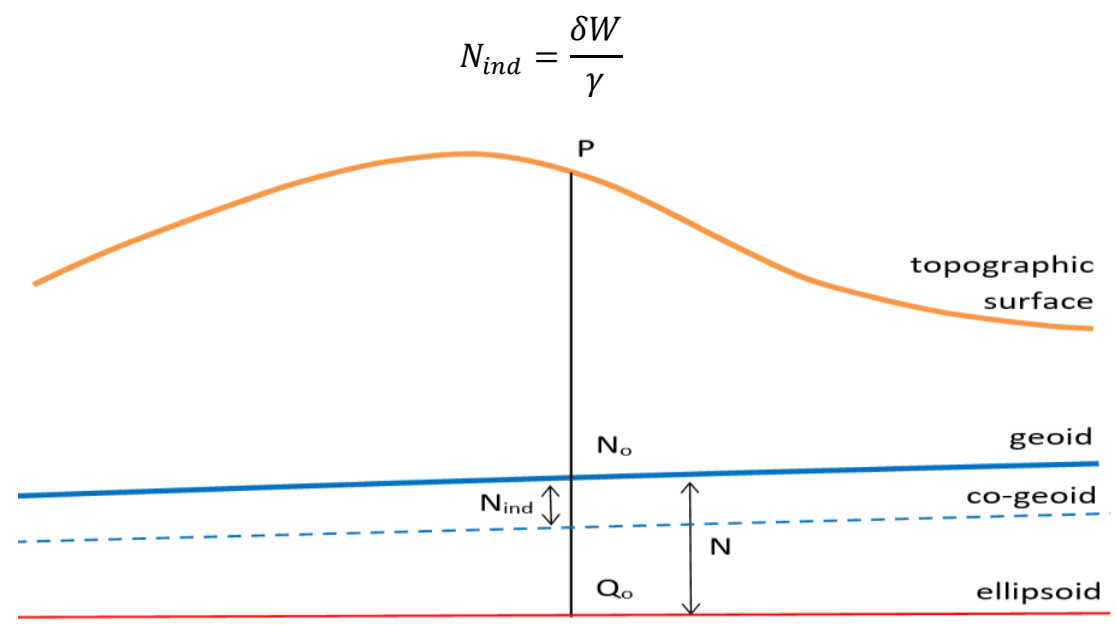

Fig. 2. Reference surfaces.

Under the assumption of a plane approximation, the term $N_{\text {ind }}$ can be written using two terms (Schwarz et al., 1990):

$$
N_{\text {ind }}=-\frac{\pi G \rho}{\gamma} h^{2}\left(x_{P}, y_{P}\right)-\frac{G \rho}{6 \gamma} \iint_{A} \frac{h^{3}(x, y)-h^{3}\left(x_{P}, y_{P}\right)}{\left[\left(x_{P}-x\right)^{2}+\left(y_{P}-y\right)^{2}\right]^{3 / 2}} d x d y
$$

$$
\begin{array}{ll}
\rho & \text { density of topography assumed to be } 2,67 \mathrm{~g} / \mathrm{cm}^{-3} \\
\left(x_{P}, y_{P}\right) & \text { coordinates of the point; } \\
(x, y) & \text { coordinates of integration points; }
\end{array}
$$



$h(x, y) \quad$ elevation model, taking into account only the masses above the geoid, i.e. only the positive elevations;
A study area.

The plane approximation of the expression of $N_{\text {ind }}$ can be write as a convolution formula (Schwarz et al., 1990):

$$
N_{\text {ind }}=-\frac{\pi G \rho}{\gamma} h^{2}-\frac{G \rho}{6 \gamma} f * h^{3}+\frac{G \rho}{6 \gamma} s h^{3}
$$

where:

$$
\begin{aligned}
& f(x, y)=\frac{1}{\left(x^{2}+y^{2}\right)^{3 / 2}} \\
& s=\iint_{A} f(x, y) d x d y
\end{aligned}
$$

\subsubsection{Contribution of the residual gravity}

The last term $N_{\Delta g}$ of equation (1) represents the contribution of the gravity residual which, taking into account the Stokes equation, is (Hofmann and Moritz, 2006):

$$
N_{\Delta g}=\frac{R}{4 \pi \gamma} \iint_{A} \Delta g(\psi, \alpha) S(\psi) d A
$$

$\gamma \quad$ normal gravity on the ellipsoid;

$R \quad$ mean earth radius;

$S(\psi) \quad$ Stokes function;

$\Delta g \quad$ reduced anomalies according to the Helmert condensation method.

Under the assumption of spherical approximation, equation (15) can be expressed in convolution form using the one-dimensional (1-D) Fourier transform (Haagmans et al., 1993):

$$
N_{\Delta g}=\frac{R \Delta \phi \Delta \lambda}{4 \pi \gamma} F_{I}^{-1}\left[\sum_{\phi^{\prime}=\phi_{I}}^{\phi_{n}} F_{I}(\Delta g \cos \phi) F_{I}(S)\right]
$$

where $F_{I}(S)$ represents the discrete Fourier transform (DFT) and $F_{I}^{-1}$ its inverse transform (IDFT). Instead, in the hypothesis of plane approximation, the Stokes function becomes (Schwarz et al., 1990):

$$
S(\psi) \approx 2 / \psi
$$

Therefore, the contribution of the gravity residue $N_{\Delta g}$, with appropriate substitutions and passing from polar coordinates $(s, \alpha)$ to Cartesian coordinates $(x, y)$, takes on the following expression:

$$
N_{\Delta g}=\frac{1}{2 \pi G} \iint_{A} \frac{\Delta g}{\left(x_{p}-x\right)^{2}+\left(y_{p}-y\right)^{2}}
$$

The equation (18) can be rewritten in terms of FFT (Fast Fourier Transform):

$$
N_{\Delta g}=\frac{1}{2 \pi G} \Delta g(x, y) * l_{p}(x, y)
$$

with $l_{p}(x, y)=1 / \sqrt{x^{2}+y^{2}}$, which is called the "kernel of the plane approximation".

To determine the $N_{\Delta g}$ term, it is necessary to calculate the value of the gravity anomalies, using the following relationship:

$$
\Delta g=\Delta g_{\text {free }}+c_{t}+\delta g
$$

$\Delta g_{\text {free }} \quad$ free-air gravity anomaly; 
$\begin{array}{ll}c_{t} & \text { terrain correction; } \\ \delta g & \text { indirect secondary effect on gravity. }\end{array}$

The indirect secondary effect on gravity can be expressed as a function of $N_{\text {ind }}$ (Heiskanen and Moritz, 1967; Kuroishi, 1993):

$$
\delta g=0.3086 N_{\text {ind }}
$$

Therefore, the residual anomaly field must first be determined, removing the effect of the short wave associated with topography and bathymetry. This correction is called "Residual Terrain Correction" RTC (Forsberg, 1984) and can be described through the following relation (Corchete et al., 2005), where the superscript "pts" denotes that the points in the study area are randomly distributed:

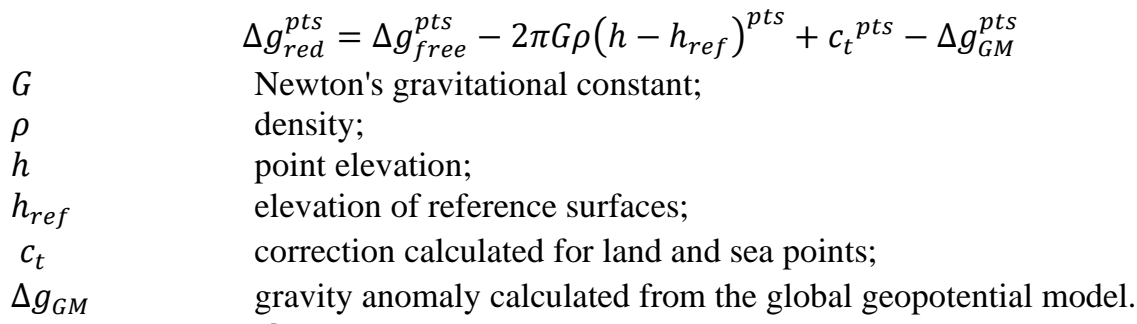

The reference surface $h_{\text {ref }}$ can be obtained by applying a 2-D low-pass filter to the elevation model.

The density value that can be used in equation (22) for the RTC correction are:

$\rho_{\text {ow }}=2,67 \mathrm{~g} \mathrm{~cm}^{-3}$ for points on the ground;

$\rho_{u w}=1,64 \mathrm{~g} \mathrm{~cm}^{-3}$ for points below water.

The density value for the correction below water is given by the difference between the density of the soil and that of the water, which is equal to $\rho_{w}=1,03 \mathrm{~g} \mathrm{~cm}^{-3}$.

For the computation of the Fourier transform, it is necessary that the data be arranged in the form of a grid; several methods and algorithms for performing this operation are available in the literature:

- $\quad$ Briggs method (Briggs, 1974);

- $\quad$ least squares collocation method (Moritz, 1980);

- $\quad$ Kriging method (Davis, 1986);

- $\quad$ spline algorithm (Smith \& Wessel, 1990).

By arranging the values of the gravity anomalies in grid form, the effect of the RTC can be restored through the following relationship (Corchete, 2010):

$$
\Delta g_{\text {red }}^{\text {grid }}=\Delta g_{\text {free }}^{\text {grid }}-2 \pi G \rho\left(h-h_{\text {ref }}\right)^{\text {grid }}+c_{t}{ }^{\text {grid }}-\Delta g_{G M}^{\text {grid }}
$$

In equations (20) and (22), the term $c_{t}$ takes into account the influence of the topography. In fact, especially in particularly steep terrain, the topography assumes a fundamental role in the calculation of the undulations. The correction $c_{t}$ of the terrain to be applied, approximating $z=h_{P}$, i.e. in the socalled "linear approximation" (Heiskanen and Moritz, 1967), is:

$$
c_{t}=G \varrho \iint_{A} \int_{h_{P}}^{h} \frac{z-h_{P}}{\left[\left(x_{P}-x\right)^{2}+\left(y_{P}-y\right)^{2}+\left(z_{P}-z\right)^{2}\right]^{3 / 2}}
$$

Equation (24), rewritten in the form of a convolution (Sideris, 1990), takes the following form:

$$
c_{t}=\frac{1}{2} G \varrho\left[f * h^{2}-2 h(f * h)+h^{2} s\right]
$$

where

$$
f(x, y)=\frac{1}{\left(x^{2}+y^{2}\right)^{3 / 2}}
$$




$$
s=\iint_{A} \frac{1}{\left(x^{2}+y^{2}\right)^{3 / 2}} d x d y
$$

As an alternative to the FFT, terrain correction can be achieved with the prism method. which consists of dividing the terrain into many prisms; depending on the method of terrain condensation, two models are available: $i$ ) Prism model; ii) Mass line. The prism model associates the density of each prism with its average height, while in the mass line model the mass of the prism is mathematically concentrated along its barycentre axis, therefore the topography contained in the prism is represented by a line (Fig. 3).
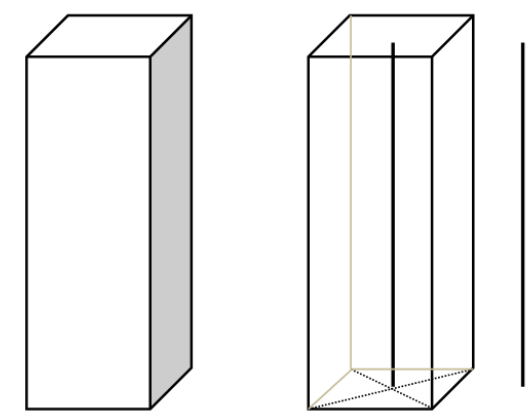

Fig. 3. Types of soil condensation: mass prism (left) and mass line (right).

In the first case, equation (25), after having reported the DTM in the form of a grid in M and $N$ cell elements of size $(\Delta \mathrm{x} ; \Delta \mathrm{y})$, can be rewritten in the following form (Yurt \& Gokalp, 2006):

$$
\begin{aligned}
c_{t}=G \rho \sum_{n=0}^{N-1} \sum_{m=0}^{M-1} & {[x \ln (y+r(x, y, z)+y \ln (x+r(x, y, z))) \cdot+} \\
& \left.\quad-z \arctan \frac{x y}{z r(x, y, x)}\right]\left.\left.\left.\right|_{x_{i}-\left(x_{n}+\Delta x / 2\right)} ^{x_{i}-\left(x_{n}+\Delta x / 2\right)}\right|_{x_{i}-\left(x_{n}+\Delta x / 2\right)} ^{x_{i}-\left(x_{n}+\Delta x / 2\right)}\right|_{x_{i}-\left(x_{n}+\Delta x / 2\right)} ^{x_{i}-\left(x_{n}+\Delta x / 2\right)}
\end{aligned}
$$

while in the second case (Yang, 1999) becomes:

$$
c_{t}=-G \rho \Delta x \Delta y \sum_{n=0}^{N-1} \sum_{m=0}^{M-1}\left[\frac{1}{r\left(x_{i}-x, y_{j}-y, 0\right)}-\frac{1}{r\left(x_{i}-x, y_{j}-y, h_{i j}-h_{n m}\right)}\right]
$$

where:

$$
\begin{array}{cl}
G & \text { Newton's gravitational constant; } \\
\rho & \text { density; } \\
\mathrm{h}_{\mathrm{ij}} & \text { point elevation }(\mathrm{i}, \mathrm{j}) ; \\
\mathrm{r} & \text { radius of the coordinate sphere in the Cartesian system }(x, y, z) .
\end{array}
$$

\subsection{Adjustment of the gravimetric geoid model}

The sum of the contributions $\mathrm{N}_{i}$ gives the undulation model according to a geophysical approach. If the $N$ model of the geoid undulation were correct, the following relationship would occur:

$$
h-H-N=0
$$

Factors causing discrepancies are (Fotopoulos, 2003):

- $\quad$ random errors in the calculation of heights $h, H, N$;

- inconsistencies of the datum intrinsic to the different types of heights;

- $\quad$ errors and distortions (errors related to the measurement of the wavelength for the geoid measurement, systematic errors related to the GNSS measurement and to the limits of the levelling network); 
- theoretical assumptions/approximations made in the treatment of the observed data (neglecting the topography of the sea or river, corrections due to the influence of the tides); instability of the reference monument station over time (geodynamic effects).

Therefore, it is necessary an "adjustment" of the geoid undulation model on the vertices deduced from the network where the orthometric height derived from a levelling (for example the fundamental network) and the ellipsoid height derived from GNSS (or Global Position System - GPS) measurement; the equation of the least squares system takes the following form:

$\begin{array}{ll} & \left(h^{G P S}-H^{\text {lev }}\right)-N^{\text {gravim }}=N^{G P S}-N^{\text {gravim }}=\delta N=l=A X \\ h^{G P S} & \text { ellipsoid height of the reference point; } \\ H^{\text {lev }} & \text { orthometric height measured by levelling; } \\ N^{\text {gravim }} & \text { geoid undulation obtained by the gravimetric method; } \\ A X & \text { surface trend; } \\ \delta N & \text { residual. }\end{array}$

Using a four-parameter model, itis possible to obtain the following formula (Isioye \& Youngu, 2009):

$$
A X=a_{0}+a_{1} \cos \varphi \cos \lambda+a_{2} \cos \varphi \sin \lambda+a_{3} \sin \varphi
$$

where $\varphi, \lambda$ are the geodetic latitude and longitude and the parameters $a_{0}, a_{1}, a_{2}$ and $a_{3}$ take into account the inconsistency between the GPS/levelling and the gravimetric geoid datum.

Subsequently, the residuals can be interpolated using the various interpolation techniques known in the literature, such as linear interpolation, kriging, etc.

\section{RESULTS}

\subsection{Computation of the geoid on Campania region (Italy)}

In the case study, the calculation of $N_{G M}$ was performed using the EGM2008 geopotential model, freely available at the following website: https://earth-info.nga.mil/php/download.php?file=egm$\underline{\text { 08interpolation }}$

Each raster file contains, in $2.5^{\prime}$ steps, the geoid undulation values. Since the area under study is less extensive than that of a "tile" of the EGM2008 model, after downloading the raster file, it was necessary to implement an algorithm in Matlab® environment to extrapolate the undulation values and performing a clip on AOI. The contribute of geoid undulation model $N_{G M}$ thus created (Fig. 4) showed a variability between $43 \mathrm{~m}$ and $50 \mathrm{~m}$.

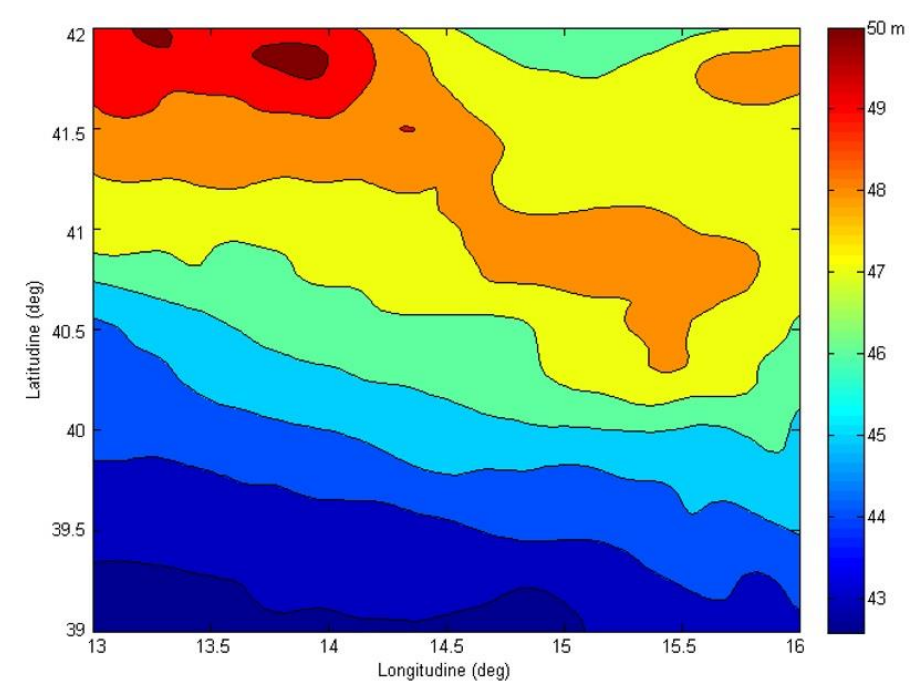

Fig. 4. Plot of the EGM2008 geoid model of the study area, contribute of $N_{G M}$. 
Moreover, from the section shown in Fig. $\mathbf{5}$ it is easy to notice how local variations over small areas are not detected by the geopotential model. For example, in the area under study, the island of Ischia, which has an extension of about $8^{\prime}$ in longitude and $5^{\prime}$ in latitude, the values at the nodes of which the grid is composed have an almost nil gradient, despite the morphology of the territory reaches altitudes up to almost $750 \mathrm{~m}$ above sea level and has rather significant gravimetric anomalies.

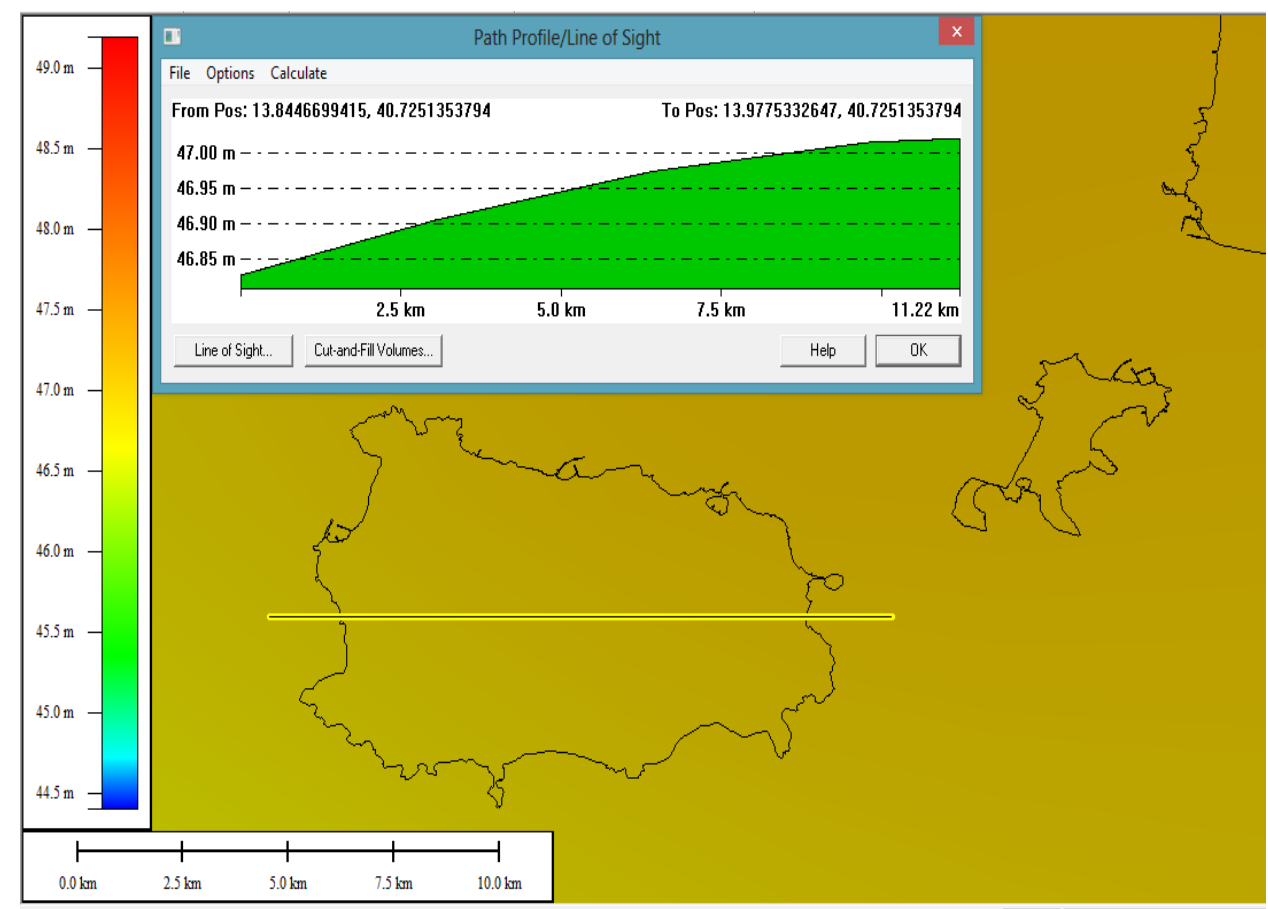

Fig. 5. Cross-section of the geoid model EGM2008 on the island of Ischia, an island close to the Italian peninsula (within Campania region).

The contribution of the indirect topographic effect $N_{\text {ind }}$ was obtained, under the assumption of plane approximation, by applying the formula (12). In Matlab® environment, an algorithm for the calculation of $N_{\text {ind }}$ has been implemented, where the convolution product between the functions in equation (14) was obtained using the Fourier transform, in particular the Fast Fourier Transformation. As regards the solution of the double integral reported in the formula (15), the Matlab® function implementing Simpson's quadrature method was used; this latter function was suitably modified in order to divide the area under study into a matrix of 200x200 elements and, on each of them, the double integral was calculated. To calculate the contribution of the indirect effect, the Shuttle Radar Topography Mission (SRTM) was used as Digital Terrain model (DTM); in this model, topographic and elevation data were collected in February 2000 by the Space Shuttle Endeavour, which used a sophisticated synthetic aperture radar-altimeter for this mission. The elementary measurement cell (pixel) corresponds to 3 square arc seconds, i.e. approximately $90 \mathrm{~m} \times 90 \mathrm{~m}$ measured on the ground, with a declared accuracy of $20 \mathrm{~m}$ in planimetry and $16 \mathrm{~m}$ in altimetry (Werner, 2001). The elevation values of this model are freely downloaded from the Consortium for Spatial Information (CGIARCSI) website.

Since the contribution of the indirect effect is closely linked to the morphology of the territory, in the study area, which does not have any major reliefs, it was found to be of little relevance; more precisely, it varied from a few centimetres to about 1 metre. It should be noted that the previous values 
are to be considered as absolute values, as the $N_{\text {ind }}$ contribution always gives rise to negative values since the masses above the geoid have been removed.

$N_{\Delta g}$ can be calculated either by the collocation method or by the Stokes formula which, under the assumption of a plane approximation and expressed in the form of a convolution, assumes the following formula (Corchete et al., 2005):

$$
N_{\Delta g}=\frac{1}{2 \pi G} \Delta g(x, y) * l_{p}(x, y)+\frac{1}{\pi G} \Delta g(x, y) \sqrt{x^{2}+y^{2}}
$$

where a second term has been added to equation (20) to eliminate singular points. A Matlab® algorithm was implemented in order to extracts the values of the residual anomalies, $\Delta g$, obtained from the relation (22). To achieve this aim, the value are gridded; therefore, the equation (22) can be written in the following way:

$$
\Delta g_{\text {red }}^{\text {grid }}=\Delta g_{\text {free }}^{\text {grid }}-2 \pi G \rho\left(h-h_{\text {ref }}\right)^{\text {grid }}+c_{t}^{\text {grid }}-\Delta g_{G M}^{\text {grid }}
$$

Since all the terms in the previous relation are not gridded, as can be observed for $\Delta g_{\text {free }}$, the first operation performed was to transform them in grid form with a spatial resolution of $2.5^{\prime}$, using "kriging" algorithm. The gravimetric values $\Delta g_{\text {free }}$, provided by the "Bureau Gravimétrique International" (BGI), are not distributed according to a regular grid but thicken where measurements were made for local surveys as shown in Fig. 6, where the gravity anomalies (free anomalies) are reported, both on land and sea.

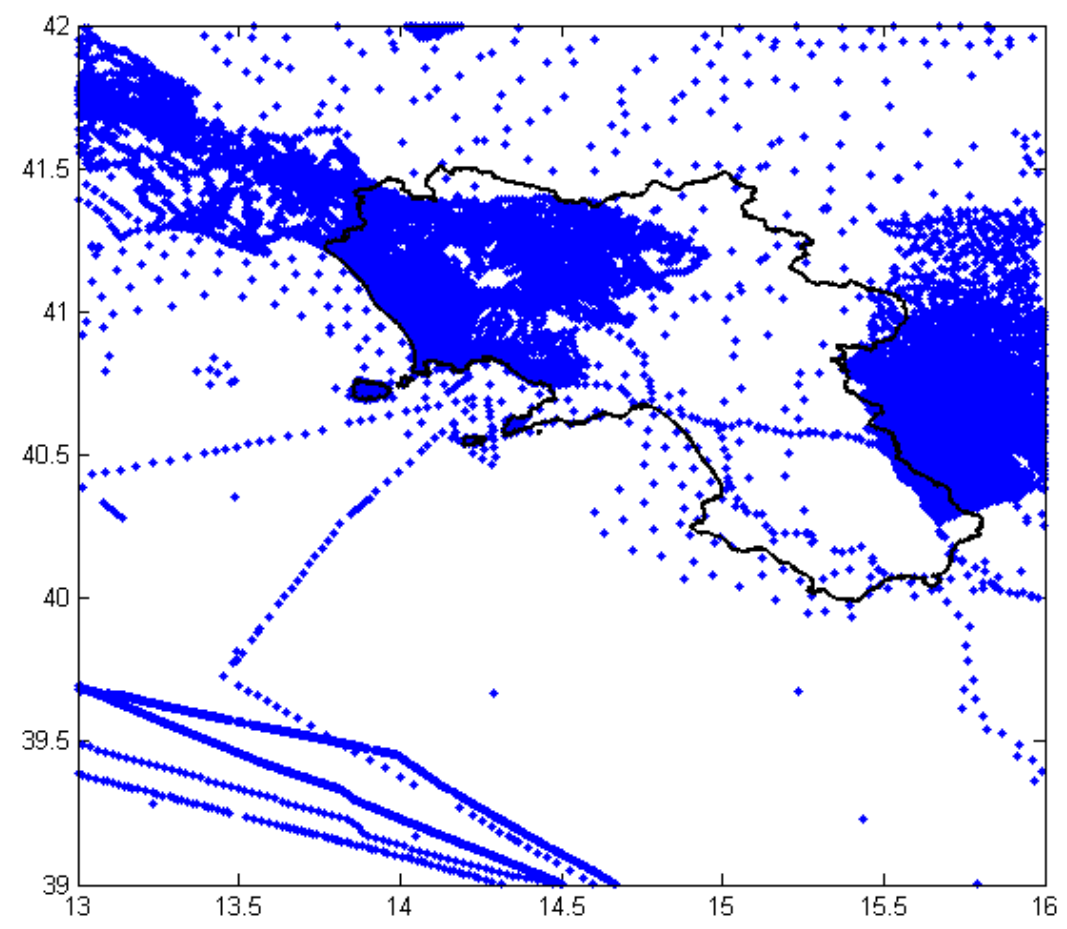

Fig. 6. Distribution of free-anomalies. 
The term $\Delta g_{G M}^{\text {grid }}$ represents the gravity anomaly, computed by the EGM2008 global geopotential model, whose grid of values with a $2.5^{\prime}$ step can be obtained from the NGA website. The data are recorded in the 'big endian file' format and, thanks to a special script in Fortran, a text file of about 4.5GB was obtained containing three grids of values ( $\mathrm{N}-\mathrm{S}$ deflection of vertical component, E-O deflection of vertical component and gravity anomalies); subsequently, with a manual editing of the data, three separate files were created. The minimum, maximum and mean value of the local gravity anomalies and those related to the geopotential model are shown in Table $\mathbf{1 .}$

Table 1.

Statistical values of gravity anomalies.

\begin{tabular}{|l|c|c|c|}
\hline & $\begin{array}{c}\text { Min } \\
(\mathrm{mgal})\end{array}$ & $\begin{array}{c}\text { Max } \\
(\mathrm{mgal})\end{array}$ & $\begin{array}{c}\text { Medio } \\
(\mathrm{mgal})\end{array}$ \\
\hline Measured anomalies $\left(\Delta g_{\text {free }}\right)$ & -117 & 161 & 38 \\
\hline Anomalies taken from EGM2008 $\left(\Delta g_{G M}\right)$ & 21 & 203 & 43 \\
\hline
\end{tabular}

The term $2 \pi G \rho\left(h-h_{r e f}\right)^{g r d}$ represents the gravimetric contribution that masses of height $\mathrm{h}$, obtained by integrating altimetric data from the SRTM height model with bathymetric data from ETOPO1 (Amante \& Eakins, 2009), produce with respect to a reference surface $h_{\text {ref }}$ obtained by applying a 2-D low-pass filter to the digital terrain model. By means of a "spatial query" in a Geographic Information Systems (GIS) environment, the land points were separated from the sea points. Indeed, spatial query make it possible to select elements in a vector layer using spatial relationships (intersect, contain, touch etc.) with elements in a second layer. As far as the terrain correction is concerned, the formula (22) valid for plane approximation was applied in the form of convolution. The trend of the contribution $c_{t}{ }^{\text {grid }}$ is of the order of some milligal. Therefore, once all the contributions of the residual anomalies $\Delta g_{\text {red }}^{\text {grid }}$ (Eq. 24) were determined using FFT, it was possible to calculate the contribution of the residual effect $N_{3}$. In this way, the three contributions of the geoid undulation, $N_{1}, N_{2}, N_{3}$, were determined; the sum of these latter terms allows to obtain a geoid model on the basis of gravimetric measurements only, i.e. the so-called gravimetric geoid.

In the determination of the gravimetric geoid model, no reference has so far been made to levelled heights and thus to the national height reference network. Therefore, an adjustment of the geoid model on the vertices taken from the levelling network is necessary; these vertices contain the value of the geoid undulation since this value was obtained as the difference of the orthometric height, derived from the levelling vertices, and the ellipsoid height obtained from the GPS measurements. At present, the Italian Military Geographic Institute (IGMI) realized approximately 20,000 km of high-precision levelling lines. Analysing the levelling network on the Campania region, it is noted that on the islands, such as Ischia, it is completely absent; this translates into the lack of reference points for verifying the geoid undulation on these areas. However, it should be noted that in this area, there is a levelling network (Galvani et al., 2021) realized by National Institute of Geophysics and Volcanology (Italian: Istituto Nazionale di Geofisica e Vulcanologia, INGV).

In order to take into account the inconsistency between the GPS/levelling datum and the gravimetric geoid datum, 10 vertices of the IGM network with a uniform distribution in the test area were chosen. By adopting a four-parameter model and constructing a least squares system in Matlab ${ }^{\circledR}$, the parameters $\mathrm{a}_{0}, \mathrm{a}_{1}, \mathrm{a}_{2}$ and $\mathrm{a}_{3}$ that characterise this inconsistency were determined. The residuals obtained from the difference between $N_{\text {gravimetrico }}$ and $N_{G P S / l i v}$, were subsequently interpolated by "kriging" method and added to the pre-adjustment $N$ model, i.e. the gravimetric one. 
In the following graph (Fig. 7) the abscissae indicate the vertices taken into consideration, while the ordinates indicate the geoid undulation values, expressed in metres. In Fig. 7, the red bar indicates the pre-adjustment undulation, the green bar the post-adjustment undulation and the blue bar the levelling reference undulation; by comparing them, it can be seen that the green bar is closer to the blue bar, denoting the improvement of the geoid model following the adjustment. It follows that the high resolution of the geoid is related to the levelling network, therefore, the higher the number of vertices with known double elevation, the higher the accuracy of the geoid model.

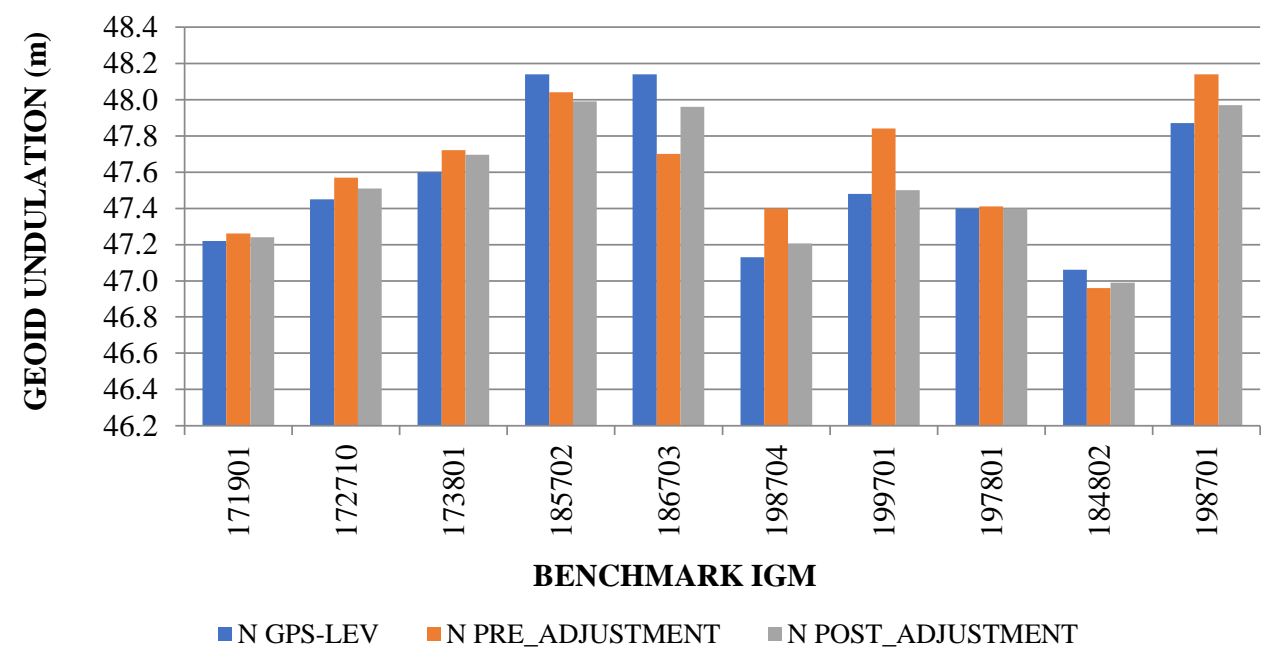

Fig. 7. Comparison of geoid undulations over ten benchmarks.

The new geoid undulation model, obtained in the GEOTRAV reference system relative to the test area, is shown in Fig. 8.

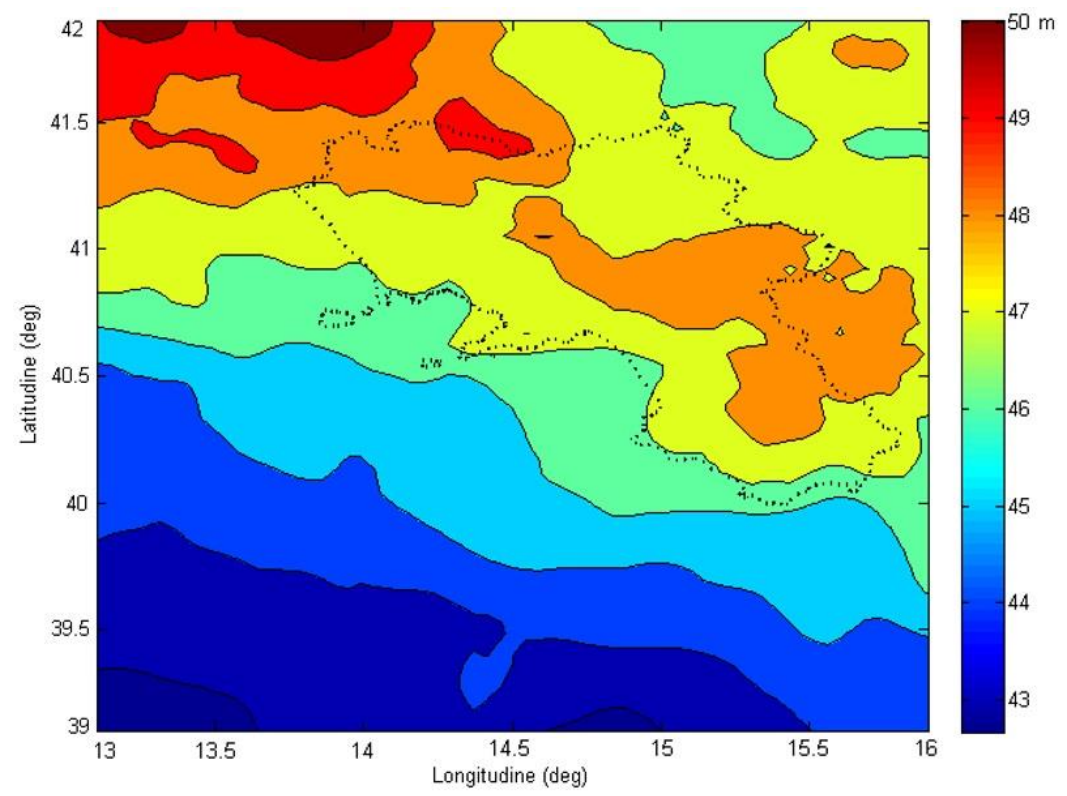

Fig. 8. Local geoid model on AOI. 


\section{2. 'Vertical shift' of the EGM2008 global geoid undulation model}

The global model provides a good part of the geoid undulation values, net of the contribution due to the influence of topography and strong gravimetric influences.

For this reason, the undulation values of the geoid model EGM2008 were compared on the Campania region, where the contribution of topography is less relevant than in other areas (e.g. the Alps), with those obtained on the test area with the remove-restore technique with subsequent adjustment on the vertices by GPS/levelling (Pepe \& Prezioso, 2016).

The differences in geoid undulation between the two models were assessed on the basis of those parameters that provide information on the characteristic of the distribution of a one-dimensional variable, namely the first-degree moment (or mean) and the standard deviation $(\sigma)$ :

$$
\begin{array}{r}
\mathrm{m}_{1}(x)=\sum_{\mathrm{i}=1}^{\mathrm{n}} x_{\mathrm{i}} f_{\mathrm{i}} \\
\sigma=\sqrt{\sigma^{2}(x)}=\sqrt{\sum_{\mathrm{i}=1}^{\mathrm{n}} v_{i}^{2} f_{i}}
\end{array}
$$

where $f_{\mathrm{i}}$ is the relative frequency and with $v_{i}$ the following quantity:

$$
v_{i}=x_{i}-\mathrm{m}_{1}(x)
$$

In this case study, the differences of geoid undulation values showed mean and standard deviation values of $m_{1}(x)=-0.21 \mathrm{~m}$ and $\sigma=0.08 \mathrm{~m}$ with minimum and maximum values, respectively $\min =-0.76 \mathrm{~m}$ and $\max =+0.52 \mathrm{~m}$.

The analysis of the statistical data leads to the application of a constant translation equal to minus $\mathrm{m}_{1}(\mathrm{x})$, to the EGM2008 model, obtaining a new local geoid model with minimum and maximum undulation difference values compared to the global one: $\min =-0.16 \mathrm{~m}, \max =+0.22 \mathrm{~m}$.

\section{CONCLUSIONS}

The development of algorithms in Matlab® environment allowed, using the remove-computerestore technique, to build a local geoid model. In this way, it was possible to obtain the values of the geoid undulation. The implementation of these algorithms in Matlab ${ }^{\circledR}$ is facilitated by the inclusion of numerous and increasingly powerful mathematical and algebraic functions in this environment.

In particular, the research that led to the building of a local geoid model allowed to highlight several aspects on the study area: $i$ ) high performance of the EGM2008 global model on the Campania region; ii) "smoothing" effect of the geoid undulation values of the EGM2008 model on the small islands; iii) improvements of the geoid model obtains by introducing into the adjustment the values of the IGM vertices determined with GPS technology and subsequently connected to the levelling network. In addition, the realization of new levelling lines would allow to obtain a higher accuracy of the geoid model and thus make it available at a higher spatial resolution.

Therefore, the geoid undulation, available in vector or raster format, can be used in several geomatics applications, such as the knowledge physical height by GNSS measurements. Indeed, GNSS-based applications are becoming increasingly common in various fields, such as topography, terrestrial or aerial photogrammetry and remote sensing.

Furthermore, once the geoid undulation model has been computed, it is possible to calculate with elevated accuracy the components of the deflection of the vertical (the meridional component $\xi$ and the East-West component or first vertical $\eta$ ) using the formulas of Vening Meisnez and useful in several geomatics applications. 


\section{R E F E R E N C E S}

Amante, C. \& B. W. Eakins. (2209). ETOPO1 1 Arc-Minute Global Relief Model: Procedures, Data Sources and Analysis, NOAA Technical Memorandum NESDIS NGDC-24, pp. 19.

Baiocchi, V., Camuccio, P., Zagari, M., Ceglia, A., Del Gobbo, S., Purri, F., ... \& Vatore, F. (2017). Development of a geographic database of a district area in open source environment. GEAM-Geoingegneria ambientale e mineraria-geam-geoengineering environment and mining, (151), 97-101.

Barzaghi, R.; Borghi, A.; Carrion, D.; Sona, G. Refining the estimate of the italian quasi-geoid. Boll. Geod. Sci. Affin. 2007, 66, 145-160.

Barzaghi, R., Carrion, D., Pepe, M., \& Prezioso, G. (2016). Computing the deflection of the vertical for improving aerial surveys: a comparison between EGM2008 and ITALGEO05 estimates. Sensors, 16(8), 1168.

Blázquez, E. B., Gil, A. J., Rodríguez-Caderot, G., De Lacy, M. C., \& Ruiz, J. J. (2003). ANDALUSGeoid2002: The new gravimetric geoid model of Andalusia (Southern Spain). Studia Geoph. et Geod., 47(3), 511-520.

Borre K. (2008). Geoid Undulations Computed from EGM96, Aalborg University.

Briggs, I.C. (1974). Machine contouring using minimum curvature, Geophysics, 39, 39-48.

Corchete, V., Chourak, M. and Khattach, D. (2005), The high-resolution gravimetric geoid of Iberia: IGG2005. Geophysical Journal International, 162: 676-684. doi: 10.1111/j.1365-246X.2005. 02690.x

Corchete V. (2010). The high-resolution gravimetric geoid of Italy: ITG2009, Journal of African Earth Sciences, 58, pp. 580-584.

Costantino, D., Pepe, M., Dardanelli, G., \& Baiocchi, V. (2020). Using optical Satellite and aerial imagery for automatic coastline mapping. Geographia Technica, 15(2), 171-190.

Davis J.C. (1986). Statistics and Data Analysis in Geology, John Wiley e Sons Inc.

El-Ashquer, M., Elsaka, B., \& El-Fiky, G. (2017). An Improved Local Geoid Model for Egypt using Satellite Geopotetial and Terrestrial Data. Al-Azhar University Civil Eng. Research Magazine (CERM), 39(2).

Erol, S., Özögel, E., Kuçak, R. A., \& Erol, B. (2020). Utilizing Airborne LiDAR and UAV Photogrammetry Techniques in Local Geoid Model Determination and Validation. ISPRS International Journal of GeoInformation, 9(9), 528.

Forsberg, R. (1984). A study of terrain reductions, density anomalies and geophysical inversion methods in gravity field modelling. Ohio State Univ Columbus Dept Of Geodetic Science and Surveying.

Fotopoulos G. (2003). An analysis on the optimal combination of geoid, orthometric and ellipsoidal height data, PhD thesis, Department of Geomatics Engineering, University of Calgary, Alberta Canada.

Galvani, A., Pezzo, G., Sepe, V., \& Ventura, G. (2021). Shrinking of Ischia Island (Italy) from Long-Term Geodetic Data: Implications for the Deflation Mechanisms of Resurgent Calderas and Their Relationships with Seismicity. Remote Sensing, 13(22), 4648.

Haagmans, R. (1993). Fast evaluation of convolution integrals on the sphere using 1D FFT and a comparison with existing methods of Stokes' integral. Manuscr. Geod., 18, 227-241.

Heiskanen W. A. \& Moritz H. (1967). Physical Geodesy, W. H. Freeman e Co Ltd, San Francisco.

Hofmann-Wellenhof, B., \& Moritz, H. (2006). Physical geodesy. Springer Science \& Business Media.

Isioye O. A. \& Youngu T. T. (2009). Global Geoid Modeling and height determination for engennering applications.

Kalu, I., Ndehedehe, C. E., Okwuashi, O., \& Eyoh, A. E. (2021). Integration of satellite geodetic observations for regional geoid modeling using remove-compute-restore technique. Earth Science Informatics, 1-19.

Kuroishi Y. (1993) Precise Gravimetric Determination of Geoid in the Vicinity of Japan. Bulletin of the Geographical Survey Institute, Vol. 41.

Lysaker, D. I., Omang, O. C. D., Pettersen, B. R., \& Solheim, D. (2007). Quasigeoid evaluation with improved levelled height data for Norway. Journal of Geodesy, 81(9), 617-627.

Mayer-Gürr, T., Behzadpour, S., Ellmer, M., Klinger, B., Kvas, A., \& Zehentner, N. (2016). ITSG-Grace2016monthly and daily gravity field solutions from GRACE.

Moritz H. (1980). Advanced Physical Geodesy, Herbert Wichmann Verlag Karlsruhe.

Pavlis, N. K., Holmes, S. A., Kenyon, S. C., \& Factor, J. K. (2012). The development and evaluation of the Earth Gravitational Model 2008 (EGM2008). Journal of geophysical research: solid earth, 117(B4). 
Oluyori, P. D., Ono, M. N., \& Eteje, S. O. (2018). Computations of Geoid Undulation from Comparison of GNSS/Levelling with EGM 2008 for Geodetic Applications. International Journal of Scientific and Research Publications, 8(10), 235-241.

Parente, C., \& Pepe, M. (2018). Uncertainty in landslides volume estimation using DEMs generated by airborne laser scanner and photogrammetry data. International Archives of the Photogrammetry, Remote Sensing and Spatial Information Sciences, 42(3/W4), 397-404.

Pavlis N.K., Factor J.K., Holmes S.A. (2007). Terrain-related gravimetric quantities computed for the next EGM, 1st Intern. Symposium of the International Gravity Field Service (IGFS), Turkey, Special Issue 18, pp. 318323.

Pavlis N. K., Holmes S.A., Kenyon S.C., Factor J.K. (2008). An Earth Gravitational Model to Degree 2160: EGM2008, General Assembly of the EGU, Vienna, April 13-18/2008.

Pepe, M. \& Prezioso, G. (2015). A matlab geodetic software for processing airborne LIDAR bathymetry data. The International Archives of Photogrammetry, Remote Sensing and Spatial Information Sciences, 40(5), 167.

Pepe, M., Costantino, D., Alfio, V. S., Angelini, M. G., \& Restuccia Garofalo, A. (2020). A CityGML Multiscale Approach for the Conservation and Management of Cultural Heritage: The Case Study of the Old Town of Taranto (Italy). ISPRS International Journal of Geo-Information, 9(7), 449.

Saleh J., Pavlis N.K. (2002) Development and evaluation of the global digital terrain model DTM2002, 3rd Meeting of the International Gravity and Geoid Commision of the International Association of Geodesy, edited by I. Tziavos, pp. 207-222.

Sansò, F. \& Sideris, M. G. (2013). Geoid Determination: Theory and Methods, Springer Nature, Switzerland, https://doi.org/10.1007/978-3-540-74700-0.

Schwarz K. P., Sideris M. G. \& Forsberg R (1990). The use of FFT techniques in physical geodesy, Geophysical Journal International, 100, pp. 485-514.

Sideris, M.G. (1990). Rigorous gravimetric terrain modelling using Molodensky's operator, Manuscr. Geod., 15, 97-106.

Sjöberg, L. E. (2005). A discussion on the approximations made in the practical implementation of the removecompute-restore technique in regional geoid modelling. Journal of Geodesy, 78(11-12), 645-653.

Smith W.H.F. \& Wessel P. (1990). Gridding with continuous curvature splines in tension, Geophysics, 55(3), 293-305.

Srinivas, N., Tiwari, V. M., Tarial, J. S., Prajapti, S., Meshram, A. E., Singh, B., \& Nagarajan, B. (2012). Gravimetric geoid of a part of south India and its comparison with global geopotential models and GPSlevelling data. Journal of earth system science, 121(4), 1025-1032.

Torge, W. (2001). Geodesy, Walter de Gruyter, Hawthorne.

Werner, M. (2001). Shuttle radar topography mission (SRTM) mission overview. Frequenz, 55(3-4), 75-79.

Yurt K. \& Gokalp E. (2006). Spherical and Planar Approach in Determination of Local Geoid: Case Study in Trabzon/Turkey, XXIII FIG Congress, Germany, 13/8/2006. 